\title{
Improving the Academic Self-Efficacy of Students Using Mobile Educational Apps in Virtual Learning: A Review
}

\author{
https://doi.org/10.3991/ijim.v15i06.20627 \\ Azham Hussain $\left.{ }^{(}\right)$ \\ Universiti Utara Malaysia, Sintok, Malaysia \\ azhain.1991@yandex.com \\ Emmanuel O.C. Mkpojiogu \\ Universiti Utara Malaysia, Sintok, Malaysia \\ Veritas University, Abuja, Nigeria \\ Celestina Chinenye Ezekwudo \\ Veritas University, Abuja, Nigeria
}

\begin{abstract}
There are several literatures pertaining to the self-efficacy of student, and educational mobile apps, but no work has been done yet on the improving the academic self-efficacy of students using mobile educational apps. This study therefore employed systematic review methodology to ascertain the factors necessary to be considered while using educational mobile apps in order to improve the academic self-efficacy of students. Hence, this paper attempts to review available literatures with the aim of capturing means of improving the academic self-efficacy of students using mobile educational apps. To achieve the stated research objective, the study applied systematic literature review methodology. Fifty (50) papers relating to academic self-efficacy of students using mobile educational apps were downloaded. Out of these papers, nineteen (19) most relevant studies were selected for review in order to extract the appropriate information needed for the analysis. The results from the review revealed that the major causes of students' low academic self-efficacy are: lack of confidence with $22.73 \%$ and others include: low self-esteem $(21.05 \%)$ and inferiority complex $(10.53 \%)$. Also, the review was able to show the three most important factors necessary for improving the academic self-efficacy of students using mobile educational apps included: teachers' message $(21.05 \%)$ and success and failure of others $(15.79 \%)$.
\end{abstract}

Keywords-Education, educational mobile app, self-efficacy

\section{Introduction}

Self-efficacy is the belief in one's capability of doing or achieving a particular goal. According to social cognitive psychologist, Bandura, self-efficacy is the concept of one's belief in performing a task. [3] views self-efficacy as a major component of [8] social-cognitive theory, which contends that behavior is strongly stimulated by self- 
influence. Self-efficacy belief as a vital personal resource has been amply documented in the meta-analyses of findings relating to different spheres of functioning, achieved under laboratory and natural conditions [7]. The construct of self-efficacy reflects an optimistic self-belief. This is the belief that one can perform unique or difficult tasks, or cope with adversity, in various domains of human functioning [8]. It is clear that Bandura's view of self-efficacy relates to the explication of self-efficacy in specific domains, rather than a global sense of competence. Academic self-efficacy therefore concentrates on the self-belief of students that they can achieve their academic or learning goals. It refers to a student's perception of their ability to engage and successfully complete academic tasks. It can be concluded that self-efficacy makes a person believe in their capability to overcome obstacle that hinders the achievement of their goals. Self-efficacy enables a student to reach their goals and dreams.

[10] argues that education is a key factor for sustainable development. The use of mobile phones, online application as tool in teaching and learning has become the integral part of the educational system. The challenges for educators and researchers are to explore how mobile technologies might be used to support learning [14]. Mobile apps are those application that are used either for pleasure or study purposes. It can take various forms and shapes e.g., games, e-learning etc. Educational mobile apps therefore are those mobile applications that facilitate teaching and learning. Mobile educational apps are introduced in educational system to enhance learning experiences and learners' self-efficacy. According to [35], the reasons for introducing mobile devices to learning outside the classroom is to enable new learning experiences as it improves learners' self-efficacy and motivates learning. According to [7], there are four main sources of self-efficacy beliefs, these include: mastery experiences, vicarious experiences, verbal persuasion, and emotional and physiological states. Mastery experiences refer to the experiences we gain when we take on a new challenge and succeed. The best way to learn a skill or improve our performance is practice, and part of the reason this works so well is because we are teaching ourselves that we are capable. Vicarious experience is simply the experience of having a role model to observe and emulate. When we have positive role models who display a healthy level of self-efficacy, we are likely to absorb some of those positive beliefs to ourselves. Vicarious experiences can come from a wide range of sources, including parents, grandparents, aunts and uncles, older siblings, teachers and administrative staff, coaches, mentors, and counselors. The verbal persuasion factor describes the positive impact that our words can have on someone's selfefficacy; telling a child that she is capable and up to facing any challenge ahead of her can encourage and motivate her, as well as adding to her growing belief in her own ability to succeed. The emotional and psychological states refer to the impacts of criticism, both positive and negative, on the mental state which could either encourage or discourage self-efficacy. The emotional stage of a student during the learning process determines how open he or she is to learning.

To enhance self-efficacy, learners should focus on ensuring that they have the opportunities they need to master difficult skills and complete challenging tasks, finding positive role models, listening to encouraging and motivating people, and taking care of their mental health. Teachers in ensuring self-efficacy in their students should ensure they have a good sense of efficacy themselves. Teaching is one such profession in 
which it is truly a boon to have a strong sense of self-efficacy. After all, teachers need it to deal with young, energetic, and/or hormonal students all day. Generally, when teachers believe in their ability to effectively instruct students, adapt the lessons to individual students' needs, etc., they have a high level of overall self-efficacy related to teaching. Self-efficacy affects students' behavioral choices, motivation, thought patterns and responses, perception of control, and academic productivity. So, this paper seeks to review the major ways of improving the academic efficacy of students using mobile educational apps.

Most students find it difficult passing examinations not because they are not intelligent but because they do not believe in themselves. Inferiority complex is the major killer of self-efficacy. This study therefore concentrates on the ways of improving the self-efficacy of students towards using mobile educational apps. The main aim of this study is to investigate and establish the ways of improving the academic self-efficacy of students using mobile educational apps. However, its specified objectives include: i) to ascertain reasons for low academic self-efficacy of students; and ii) to find out factors that can improve the academic self-efficacy of students using mobile educational apps. In order to thoroughly look into ways of improving self-efficacy through the use mobile educational apps, this study will seek to answer the following questions: i) what are the reasons for students' low academic self-efficacy? and ii) what are the factors that can enhance the improvement of the academic self-efficacy of students using educational mobile apps? The organization of this research paper begins with a general introduction in section one and the rest parts are as follows: section two discusses the literature review; section three discusses the methodology. Section four is about the results and discussion of findings; section five finally concludes the paper.

\section{$2 \quad$ Literature Review}

This section reviews various studies done on students' academic self-efficacy, the use of educational apps in teaching and learning [39]. The work of [27] presented some innovative applications which address the needs of learners from kindergarten to the university level [6]. These apps could be used to improve arithmetic skills, graphs' representation, geometrical objects construction, algebra problem solving and mathematical programming. The results of the studies revealed that online and mobile learning applications motivated the students, making mathematics course more enjoyable and interactive than the ordinary teaching practices. In addition, [36] created an interesting mobile gaming and learning environment, based on geographical reality, maps and location technologies, to support 12-14-year-old students. The app, MobileMath is played on a mobile phone with a GPS receiver. The basic goal of the experiment was to help students experience mathematical concepts in the physical world. Users, playing in teams, gain points by creating virtually constructed mathematical shapes (squares, rectangles or parallelograms). The construction process was done by physically walking and clicking on the location for each vertex. The authors carried out a pilot study with 60 students in three different schools. After the game, 54 of the players completed a 
questionnaire. The students understood easily the goal and the rules of MobileMath but it did not address the self-efficacy of the students.

In the paper, "An Investigation of Effectiveness of Mobile Learning Apps in Higher Education in India", [29] findings represented the opinions of different levels of students from different universities from different parts of India. The results indicated that the mobile learning apps can be very useful in the higher education environment. Furthermore, the results showed that the 40 students had adequate knowledge and awareness to use mobile technology and the Internet in their educational environment. According to a study on "Smartphone Habits and Behaviors in Supporting Students SelfEfficacy", there is a significant convergent between the exponential use of smartphones and an academic activity especially in mobile learning. Smartphone help students in improving their confidence and understanding of mobile learning. Whenever students participate in mobile learning, they interpret their performance, accomplishment and experiences to develop beliefs about their ability to engage in similar activities [19-23]. While, similar activities are bounded with the smartphone habits and internet literacy level. If these activities are consistently successful, they tend to raise self-efficacy or conversely, if these activities produce failure then it leads to low self-efficacy. However, the study did not consider ways of improving the academic self-efficacy of students using mobile learning apps.

In a study using a gamified mobile app to increase student engagement, retention and academic achievement, the effectiveness of a gamified mobile app was evaluated as a learning tool. The relationships between student retention rates, academic achievement and the app usage were studied, with a number of positive correlations emerging. With interdisciplinary comparisons deemed problematic due to small cohort numbers, combining accounting and several sciences cohorts into one larger sample allowed for more statistically significant findings to be generated. But on a limiting side, the study focused specifically on the gamified aspect of the mobile apps leaving out other apps. Further, [38], posits that mobile devices such as laptops, personal digital assistants, and mobile phones have become a learning tool with great potential in both classrooms and outdoor settings [40]. They went on to review papers related to the integration of mobile devices in teaching and learning. They also sought to determine which domain subjects are being taught, what kinds of mobile device and software are being used, where such programs take place, how the devices are used in teaching, and the duration of the interventions. But the work however, did not say anything concerning the impact of mobile educational apps on self-efficacy. Also, [11] assert that using mobile phone applications in teaching and learning provides positive ideas and benefits that motivate students to learn and understand better. So according to them positive ideas can be developed in a student when there are required materials needed in learning. So, proper use of mobile phone applications increases the students' academic self-efficacy directly or indirectly.

Mobile applications, with their increasing functionality, can support the design and implementation of diverse learning activities in various settings [28]. Furthermore, [3942] investigated the effectiveness of mobile learning apps in higher education institutions in India. The study evaluated the role of mobile learning apps in students' life. However, the study was only limited to Indian students and also, not much was said 
about how these mobile applications can enhance education. Mobile devices are commonly used among higher education students and are becoming the daily culture of almost every student. Mobile apps are one of the applications used in teaching and learning via mobile devices. However, it is important that students should have positive attitudes towards adopting these mobile devices in learning [2]. More so, [17] found that the incorporation of mobile devices into an elementary botany class contributed to slightly higher post-test scores than for those students who completed the same activity with a book. Therefore, by implication this means that the use of mobile application can enhance students' performance and as a result improve their academic self-efficacy. Studies have shown that the use of mobile applications blend teaching styles with the learning styles of students making learning a new experience for the students [33] and students are also highly motivated by the use of mobile devices and applications in learning as the relationship between students and student-teacher relationship improved.

[25] Defined academic self-efficacy as the student's perception of their ability to engage and successfully complete academic tasks. Self-efficacy affects students' behavioral choices, motivation, thought patterns and responses, perception of control, and academic productivity. Success is the greatest factor affecting a student's self-efficacy and gifted elementary school students are regularly successful academically in mainstream classrooms. In previous study, he emphasized the ways to develop, identify, validate, and find the reliability of item composition of ASES (academic self-efficacy) for Filipino junior high school students, emphasizing new factors associated with academic self-efficacy. Also, [26] reported in [16] conducted a study with 252 students at a university in Northern Portugal, they found that self-efficacy and environmental support were predictive of goal progress and academic adjustment. Students reported gains in their academic functioning when they possess stronger self-efficacy and environmental support. Therefore, students with poor environmental support perform badly in any assessment, with a consequent low self-efficacy. Individual with low sense of efficacy when exposed to chronic occupational stressors will increase vulnerability to burnout because they cannot manage job demands with pessimistic attitude [34]. Therefore, it can be deduced that one of the reasons for students' low academic self- efficacy is fear and inferiority complex.

An effective mechanism for improving self-efficacy, motivation and achievement may induce the students to acquire and develop self-regulating learning strategies [32]. [37] concludes that students who believe that intelligence is changeable and may be modified by effort have high self-efficacy and confidence in their academic performance. Similar findings suggest that self-efficacy can be enhanced and developed [15]. Thus, enlightening students about developing their self-efficacy and also strengthening their belief that their performance can be improved may ensue in additional effort and hard work. Academic goals such as being open to new experiences, getting superior grades, surpassing other students, proving intelligence through school work are embraced by students who possess self-efficacy. Against this back drop, there are students with lower self-efficacy who assume that intelligence is an entity that offers no possibility of improvement, who feel they would not be able to succeed in university, and therefore are less likely to target any kind of goal, mastery or performance. Thus, there 
is an intriguing relationship between the level of self-efficacy of students, their implicit beliefs, and their inclinations in choosing a target, mastery or performance.

Bandura's social cognitive theory supports this study. As opined by [9], "personality theories focus on the Social Cognitive Theory of Bandura. It is a learning theory based on the ideas that people learn by watching what others do, and that human thought processes are central to understanding personality. This theory provides a framework for understanding, predicting and changing human behavior which includes: attention, retention, reproduction, and motivation. Imitating a role model motivates learners. Bandura states a number of motives which includes: past reinforcement, promised reinforcement and vicarious reinforcement. Albert Bandura's framework had a large impact on personality theory and therapy. His action-oriented, problem-solving approach appeals to those who want to make changes, rather than simply philosophize.

\section{$3 \quad$ Methodology}

In order to find out existing literature that discussed the improvement of self-efficacy of students using mobile educational apps in virtual learning, this study used systematic literature review approach to search for the relevant journals and conference proceedings on academic self-efficacy of students, educational mobile apps and mobile apps respectively. This systematic review was carried out based on the restrictions defined by [24] (see also [23]). The activities in the systematic review are in phases and include: planning the review as a first phase, conducting the review as a second phase and presentation of results as the third phase. At the completion of the three phases, the result of the analysis would have been presented. The aim of the study was to find important, relevant and appropriate materials related to the improvement of self-efficacy of students via the use of mobile educational apps in virtual learning. This research employs primary and secondary search. The primary search was done using Internet databases for highly ranked journal and conference papers centered on the area of improving the academic self-efficacy of students using mobile educational apps in virtual learning. The secondary search was carried out through citation and references gotten in the course of the primary search. However, prominent emphasis was given to relevant studies ranging from the year 2005 to 2019. This provided current issues on the improvement of the academic self-efficacy of students using mobile educational apps in virtual learning. Literatures on improvement of academic self-efficacy of students are however, very limited. Table 1 below describes the selected journals and conference proceedings. The papers selected for the review were gotten from the following journal: 
Table 1. Selected Journals and Conference Proceedings, Number of Papers and year

\begin{tabular}{|l|c|c|}
\hline \multicolumn{1}{|c|}{ Journals/ Conference papers } & Number of papers & Year \\
\hline Journal of Computer Assisted Learning & 1 & 2009 \\
\hline Proceedings of the European Conference on Game Based Learning & 1 & 2008 \\
\hline ZDM & 1 & 2010 \\
\hline Journal of International Cooperation in Education & 1 & 2005 \\
\hline Journal of Frontiers in Education & 1 & 2018 \\
\hline International Journal of Interactive Mobile Technologies (iJIM) & 1 & 2015 \\
\hline School of Education and Counseling Psychology (SECP) conference papers & 1 & 2012 \\
\hline International Journal of Educational Technology in Higher Education & 1 & 2017 \\
\hline Journal of Educational, Health and Community Psychology & 1 & 2013 \\
\hline Journal of Education and Practice & 1 & 2015 \\
\hline IOSR Journal of Humanities And Social Science (IOSR-JHSS) & 1 & 2017 \\
\hline International Journal of Academic Research in Business and Social Sciences & 1 & 2017 \\
\hline International Journal for the Scholarship of Technology Enhanced Learning & 1 & 2017 \\
\hline European Journal of Open Education and E-learning Studies & 1 & 2019 \\
\hline 4th International Conference on Advanced Education and Management & 1 & 2017 \\
\hline ICAEM) & 1 & 2017 \\
\hline International Journal of Information Studies \& Libraries & 1 & 2010 \\
\hline Journal of Social Sciences & 1 & 2015 \\
\hline Proceedings of ICERI 2015 Conference & 1 & 2015 \\
\hline Journal of computer and education & 19 & \\
\hline Total & & \\
\hline
\end{tabular}

The selection of appropriate papers was from both journals and conference proceedings centered on the area of improving the academic self-efficacy of students using mobile educational apps in virtual learning. However, the search and data capture was based on the following key words: self-efficacy, academic self-efficacy, mobile educational apps and a review of empirical papers. In conducting the review, papers selected were downloaded and the abstract of each was carefully read together with the introduction in other to know its significance to the study. Fifty papers were downloaded from both journals and conference proceedings. However, only relevant papers with important contributions were selected for further reading, as such only nineteen (19) papers was eventually used. Table 1 shows the number of papers selected according to Journals and Conference proceedings. In addition, Table 2 displays the number of papers selected per journal or conference proceedings. One article was selected from each journal. 
Table 2. List of selected papers

\begin{tabular}{|c|l|c|}
\hline Paper ID & \multicolumn{1}{|c|}{ Authors name } & Year \\
\hline E1 & Frohberg, et al. & 2009 \\
\hline E2 & Wijers, et al. & 2008 \\
\hline E3 & Wijers, et al. & 2010 \\
\hline E4 & Chimombo. & 2005 \\
\hline E5 & Angelo & 2018 \\
\hline E6 & Athanasios \& Marios & 2015 \\
\hline E7 & Lauren & 2012 \\
\hline E8 & Dan et al. & 2017 \\
\hline E9 & Alay & 2013 \\
\hline E10 & Yaman & 2015 \\
\hline E11 & Annet et al. & 2017 \\
\hline E12 & Ahmad et al. & 2017 \\
\hline E13 & Hannah & 2017 \\
\hline E14 & Kagenyi & 2019 \\
\hline E15 & Jin X.U. E., et al & 2017 \\
\hline E16 & Mohd \& Aditya & 2017 \\
\hline E17 & Habibah & 2010 \\
\hline E18 & Maria João et al & 2015 \\
\hline E19 & Yao-Ting & 2015 \\
\hline
\end{tabular}

In carrying out this research different databases were used such as Google Scholar, Mendeley, Researchgate and Academia.edu. In the four databases used, a total number of fifty articles were found, and nineteen articles were finally selected for the research paper. Table 3 below shows the different database consulted and the total number of articles used.

Table 3. Database and selected articles

\begin{tabular}{|l|c|c|c|}
\hline \multicolumn{1}{|c|}{ Database } & Articles found & Article duplicated & Articles selected \\
\hline Google scholar & 20 & 7 & 7 \\
\hline Mendeley & 5 & 4 & 1 \\
\hline Research gate & 7 & 3 & 5 \\
\hline Academia.edu & 8 & 2 & 6 \\
\hline Total & 50 & 16 & 19 \\
\hline
\end{tabular}

\section{$4 \quad$ Result and Discussion of Findings}

After the detail study of the selected papers, the answers obtained for each of the research questions were based on the reasons for students' low academic self-efficacy and the factors that can improve their academic self-efficacy in the use mobile educational apps in virtual learning. The results are presented in Table 4 and Table 5. Obviously, the result revealed that improving the academic self-efficacy of students using mobile educational apps in virtual learning can be achieved. The frequency of occurrence (in percentage) of the reasons for students' low-self efficacy and the factors 
leading to improving their academic self-efficacy using mobile educational apps are based on the reviewed papers as shown on the tables below.

Table 4. Reasons for student's low self-efficacy

\begin{tabular}{|l|c|c|}
\hline The Reasons for student's low academic self-efficacy & Frequencies of Studies & Percentage \\
\hline Low self-esteem & 4 & $21.05 \%$ \\
\hline Inferiority complex & 2 & $10.53 \%$ \\
\hline Lack of confidence & 5 & $22.73 \%$ \\
\hline
\end{tabular}

Table 5. Factors for improving students' academic self-efficacy using mobile educational apps in virtual learning

\begin{tabular}{|l|c|c|}
\hline \multicolumn{1}{|c|}{ Factors } & Frequencies of Studies & Percentage \\
\hline Teachers' message & 4 & $21.05 \%$ \\
\hline Success and failure of others & 3 & $15.79 \%$ \\
\hline Students' earlier academic record & 1 & $5.26 \%$ \\
\hline Verbal persuasion & 2 & $10.53 \%$ \\
\hline Physiological factors & 2 & $10.53 \%$ \\
\hline Vicarious experience & 2 & $10.53 \%$ \\
\hline Enactive attainment & 2 & $10.53 \%$ \\
\hline
\end{tabular}

Furthermore, the results obtained from the review of the selected studies as shown in table 4 indicate that reason for low academic self-efficacy of students are: low selfesteem $(21.05 \%)$, inferiority complex $(10.53 \%)$ and lack of experience $(22.73 \%)$. Table 5 discloses that $15.79 \%$ of the factors leading to improving the academic self- efficacy of students using mobile educational apps is success and failure of others, $5.26 \%$ is students earlier academic records, $21.05 \%$ is teachers message and $10.53 \%$ goes to verbal persuasion, physiological factors, vicarious experience and enactive attainment respectively.

\section{Conclusion}

With the inception of mobile applications in schools, teaching and learning have been of great difference. The educational planners and teachers have a lot to say about the advantages and benefits of mobile apps in virtual teaching and learning. This paper reviewed the previous published literature on academic self-efficacy of students and educational mobile apps in virtual teaching and learning and presents the results. In the course of the study, fifty papers were downloaded out of which only nineteen papers were finally selected. All the selected papers were adequately read through to get the expected result based on the objectives of the study. Thus, the results obtained from the review of the selected studies indicate that the reasons for low academic self-efficacy of students are: low self-esteem, inferiority complex, lack of experience and lack of confidence. The study found that $4.55 \%$ of the factors leading to improving the academic self- efficacy of students using mobile educational apps is success and failure of others, $13.64 \%$ is students earlier academic records, $4.55 \%$ is teachers' message and 
$18.18 \%$ goes to verbal persuasion, physiological factors, vicarious experience and enactive attainment respectively.

\section{References}

[1] Abdur R., Yulia T. S., \& Muhammad A. (2018). Smartphone Habits and Behaviors in Supporting Students Self-Efficacy. iJET, 13(2).

[2] Ahmad F. M. A, Syaza H. Z., Wong S. L., \& Wan M. W. (2017). The Influence of Mobile Self-efficacy, Personal Innovativeness and Readiness towards Students' Attitudes towards the use of Mobile Apps in Learning and Teaching. International Journal of Academic Research in Business and Social Sciences, 7. https://doi.org/10.6007/ijarbss/v7-i14/3673

[3] Alay A., (2013). Effects of Self-Efficacy on Students' Academic Performance. Journal of Educational, Health and Community Psychology, 2(1).

[4] Angelo R.D. (2018). The Development of Academic Self-Efficacy Scale for Filipino Junior High School Students. Journal of Frontiers in Education, 3(19): 1-11. https://doi.org/ $\underline{10.3389 / \text { feduc. } 2018.00019}$

[5] Annet P. B., \& Prakasha G.S., (2017). Uses of Mobile Apps in Teaching and Learning. IOSR Journal of Humanities and Social Science (IOSR-JHSS), 22(12): 38-40.

[6] Athanasios S. D., \& Marios A. P. (2015). A Review of Mobile Learning Applications for Mathematics. iJIM, 9(3): 18-23.

[7] Bandura, A (2000). Social Foundations of Thought and Action. New York, NY, USA: Prentice-Hall.

[8] Bandura, A. (1997). Self-Efficacy: The Exercise of Control. New York, NY: W. H. Freeman.

[9] Boeree George C. (2015). Personality Theories. Albert Bandura Shippensburg University.

[10] Chimombo, J.P.G. (2005): Issues in basic education in developing countries: an exploration of policy options for improved delivery. Journal of International Cooperation in Education. 8 (1): 129-152.

[11] Cui, G., \& Wang, S. (2008). Adopting cell phones in EFL teaching and learning. The University of Southern Mississippi. 1(1): 69-80.

[12] In Mohammed A. A F.\& Ala' Khalid A., (2018). Using mobile in teaching and learning processes, International Journal of Research in English Education. 3 (2).

[13] Dan H, Daniel E., Grainne O., Daniel L., \& Ekaterina P., (2017). Using a gamified mobile app to increase student engagement, retention and academic achievement. International Journal of Educational Technology in Higher Education. 14(31).

[14] Frohberg, D, Göth, C., \& Schwabe, G. (2009). Mobile learning projects - a critical analysis of the state of the art. Journal of Computer Assisted Learning. 25: 307-331. https://doi.org/10.1111/j.1365-2729.2009.00315.x

[15] Gardner, H. (1983). Frames of Mind: The Theory of Multiple Intelligences. New York: Basic Books.

[16] Habibah E., Nooreen N., \& Rahil Hj. M. (2010). Achievement Motivation and Self-Efficacy in Relation to Adjustment among University Students. Journal of Social Sciences. 6 (3): 333 339. https://doi.org/10.3844/jssp.2010.333.339

[17] Hannah B. M., \& Joshua A. C (2017). Mobile Learning and its Effects on Academic Achievement and Student Motivation in Middle Grades Students. International Journal for the Scholarship of Technology Enhanced Learning. 1(2): 91-110.

[18] Hussain, A., Mkpojiogu, E.O.C., \& Kamal, F.M. (2016). A systematic review on usability evaluation methods in m-commerce apps. Telecommunication, Electronic \& Computer Engineering (JTEC). 8(10): 29-34. 
[19] Hussein, I., Hussain, A., Mkpojiogu, E.O.C., \& Nathan, S.S. (2019). The state of user experience design practice in Malaysia. International Journal of Innovative Technology and Exploring Engineering: 8(8S): 491-497.

[20] Hussain, A., Hussein, I., Mkpojiogu, E.O.C., \& Sarlan, A. (2019). The state of user experience design (UXD) practice in Malaysia: an in-situ interview approach. International Journal of Innovative Technology and Exploring Engineering: 8(8S): 498-505.

[21] Hussain, A., \& Mkpojiogu, E.O.C. (2017). Predicting the perceived worth of software products requirements with customer satisfaction. Advanced Science Letters. 23(5): 4269-4273. https://doi.org/10.1166/asl.2017.8245

[22] Hussain, A., Mkpojiogu, E.O.C., \& Nawi, M.N.M. (2017). Capturing customer satisfaction and dissatisfaction in software requirements elicitation for features in proposed software systems. Journal of Engineering and Applied Sciences (JEAS). 12(21): 5590-5597.

[23] Hussain, A., Mkpojiogu, E.O.C. \& Yusof, M.M (2016). Perceived usefulness, perceived ease of use, and perceived enjoyment as drivers for the user acceptance of interactive mobile maps. Proceedings of the $1^{\text {st }}$ International Conference on Applied Science and Technology (ICAST'16), Kedah, Malaysia. AIP Conf. Proc. 1761 (1): 020051, https://doi.org/10.1063/ 1.4960891

[24] Kitchenham B. (2004). Procedures for Performing Systematic Reviews. Keele, UK, Keele University. 33: 1-26.

[25] Lauren M. (2012). Developing Academic Self-Efficacy: Strategies to Support Gifted Elementary School Students. School of Education and Counseling Psychology.

[26] Lent, R.W., Taveira M.C., Sheu, H.B., \& Singley, D. (2009). Social cognitive predictors of academic adjustment and life satisfaction in Portuguese college students: A longitudinal analysis. J. Vocat. Behav. 74: 190-198. https://doi.org/10.1016/j.jvb.2008.12.006

[27] Maria J. F., Fernando M., Carla S. P., \& Natercia D. (2015). The Role of Mobile Technologies in the Teaching/Learning Process Improvement in Portugal. Proceedings of ICERI2015 Conference 16th-18th November 2015, Seville, Spain.

[28] Milrad, M., Jackson, M.H., \& Bergman, D. (2005). Exploring the potential of mobile services to support learning and communication in university classes. IEEE International Workshop on Wireless and Mobile Technologies in Education. IEEE Computer Society. 107-111. https://doi.org/10.1109/wmte.2005.24

[29] In Jin X., Xue Z., \& Heng L. (2017). Effects of Mobile Learning on Academic Performance and Learning Attitude in a College Classroom. 4th International Conference on Advanced Education and Management (ICAEM 2017).

[30] Mohd S. A., \& Aditya T. (2017). An Investigation of Effectiveness of Mobile Learning Apps in Higher Education in India. International Journal of Information Studies \& Libraries, 2(1), 33-41.

[31] Mohd S.A. \& Aditya T. (January, 2017). An Investigation of Effectiveness of Mobile Learning Apps in Higher Education in India. International Journal of Information Studies \& Libraries. 2(1): 33-41.

[32] Phillips, p., Abraham, C., \& Bond, R. (2003). Personality, Cognition and university students' examination performance. European journal of personality. 17: 435-445. https://doi.org/10. 1002/per.488

[33] Rossing, J., Miller. W., Cecil. A., \& Stampee, S. (2012). iLearning: the future of higher education? Student perceptions on learning with mobile tablets. Journal of the scholarship of teaching and learning. 1-26.

[34] Schmitz, G. S. (2000). Structure and dynamics of teacher self-efficacy: a protective factor against strain and burnout? http//www/diss.fu-berlin.de/2000/29/indexe.html 
[35] Wijers, M., Jonker, V., \& Drijvers, P. (2010). Mobile Math: exploring mathematics outside the classroom. ZDM. 42 (7): 789-799. https://doi.org/10.1007/s11858-010-0276-3

[36] Wijers, M., Jonker, V., \& Kerstens, K. (2008). MobileMath: The Phone, the Game and the Math. In Proceedings of the European Conference on Game Based Learning, Barcelona. 507-516.

[37] Yaman K., (2015). Self-Efficacy and Academic Achievement - A Case from Turkey. Journal of Education and Practice. 6 (29).

[38] Yao-Ting S., Kuo-En Ch., \& Tzu-Chien L., (2017). The effects of integrating mobile devices with teaching and learning on students' learning performance: A meta-analysis and research synthesis. Journal of Computer and Education. 96(2016): 252-275. https://doi. org/10.1016/j.compedu.2015.11.008

[39] Korlan Zhampeissova, Irina Kosareva, Uliana Borisova. (2020). Collaborative Mobile Learning with Smartphones in Higher Education. International Journal of Interactive Mobile Technologies. 14(21): 4-18. https://doi.org/10.3991/ijim.v14i21.18461

[40] Ahlam Mohammed Al-Abdullatif, Azza Ali Gameil. (2020). Exploring Students' Knowledge and Practice of Digital Citizenship in Higher Education. International Journal of Emerging Technologies in Learning. 15(19): 122-142. https://doi.org/10.3991/ijet. v15i19.15611

[41] Athanasios S. D.\& Marios A. P. (2015). A Review of Mobile Learning Applications for Mathematics. International Journal of Interactive Mobile Technologies (iJIM). 9(3): 18-23.

[42] Mohd Shoaib Ansari, Aditya Tripathi. (2017). An Investigation of Effectiveness of Mobile Learning Apps in Higher Education in India. International Journal of Information Studies \& Libraries. 2(1): 33-41.

\section{Authors}

Azham Hussain is the Associate Professor of Software Engineering at School of Computing, Universiti Utara Malaysia,06010 UUM, Kedah, Malaysia. He is the founder of Human-Centered Computing Research Group, which is affiliated with the Software Technology Research Platform Center at School of Computing, Universiti Utara Malaysia. Azham Hussain is a member of the US-based Institute of Electrical and Electronic Engineers (IEEE), and actively involved in both IEEE Communications and IEEE Computer societies. azhain.1991@yandex.com

Emmanuel O.C. Mkpojiogu is a Lecturer at Department of Computer and Information Technology, Veritas University, Abuja, Nigeria. Currently, he is a PhD student at School of Computing, Universiti Utara Malaysia. The research area is User Experience, Human Computer Interaction and Software Engineering. He has published many articles in reputable Scopus indexed journals. emelnuel@ hotmail.com

Celestina Chinenye Ezekwudo is a researcher with the Department of Science Education, Faculty of Education, Veritas University, Abuja, Nigeria. celestinachychy@gmail.com

Article submitted 2020-12-18. Resubmitted 2021-01-26. Final acceptance 2021-01-28. Final version published as submitted by the authors. 